Youssef El Alaoui, Jésuites, Morisques et Indiens. Étude comparative des méthodes d'évangélisation de la Compagnie de Jésus d'après les traités de José de Acosta (1588) et d'Ignacio de Las Casas (1605-1607)

Paris, Honoré Champion, coll. «Études et essais sur la Renaissance », LXV, 2006, $677 \mathrm{p}$.

Daniel-Odon Hurel

\title{
OpenEdition
}

Édition électronique

URL : http://journals.openedition.org/assr/6082

DOI : 10.4000/assr.6082

ISSN : $1777-5825$

Éditeur

Éditions de l'EHESS

Édition imprimée

Date de publication : 1 juin 2007

Pagination : $97-251$

ISBN : 978-2-7132-2143-9

ISSN : 0335-5985

Référence électronique

Daniel-Odon Hurel, « Youssef El Alaoui, Jésuites, Morisques et Indiens. Étude comparative des méthodes d'évangélisation de la Compagnie de Jésus d'après les traités de José de Acosta (1588) et d'Ignacio de Las Casas (1605-1607) », Archives de sciences sociales des religions [En ligne], 138 | avril - juin 2007, document 138-37, mis en ligne le 11 septembre 2007, consulté le 21 septembre 2020. URL : http:// journals.openedition.org/assr/6082 ; DOI : https://doi.org/10.4000/assr.6082

Ce document a été généré automatiquement le 21 septembre 2020.

() Archives de sciences sociales des religions 


\section{Youssef El Alaoui, Jésuites, Morisques et Indiens. Étude comparative des méthodes d'évangélisation de la Compagnie de Jésus d'après les traités de José de Acosta (1588) et d'Ignacio de Las Casas (1605-1607)}

Paris, Honoré Champion, coll. «Études et essais sur la Renaissance », LXV, 2006, 677 p.

\section{Daniel-Odon Hurel}

L'histoire comparée des théories et pratiques missionnaires trouve dans le cas de l'Espagne et des jésuites des années 1560-1610 un terrain particulièrement adapté. L'auteur de cette thèse a donc choisi d'étudier les méthodes et les attitudes de certains jésuites dans le cadre de la politique d'évangélisation et d'assimilation des morisques et des indiens, prenant appui essentiellement sur les écrits d'Ignacio de Las Casas (fils de morisque, 1550-1608) consacrés à la conversion des morisques et de José de Acosta (né dans une famille de conversos, 1540-1600), tournés vers l'évangélisation des indiens. Le choix de ces deux auteurs trouve toute sa justification dans la contextualisation comparée de leur production et de leur action dans les dernières décennies qui précèdent, en 1609, l'expulsion des morisques. Éditant quatre mémoires de Las Casas (on regrettera cependant, malgré une annotation soignée et judicieuse, l'absence d'une traduction française), l'auteur s'attache à comparer les idées développées par le jésuite avec celles d'autres acteurs de l'évangélisation des morisques et des indiens, et à analyser les conceptions des uns et des autres concernant l'apprentissage des langues et l'éducation des enfants. Pour ce faire, Y. El Alaoui compare le synode de Guadix (1554) et le concile de Lima III (1583), instrument de réforme de l'Église mais aussi de «réformation » des mœurs ayant pour objectif l'acculturation des morisques et des 
indiens pour les couper de leur monde traditionnel. Dans les deux cas, l'auteur met en valeur l'existence d'un programme d'enseignement minimal comparable, l'intérêt pour la langue des néophytes qu'il convient d'apprendre pour pouvoir rendre plus efficaces les missions et la nécessité de lutter contre les expressions culturelles propres. Cette position de l'Église officielle tient compte, non sans tensions parfois, des idées développées par la Compagnie de Jésus qui sont ici rappelées avec l'attachement d'Ignace de Loyola pour la conversion des musulmans et l'arrivée des jésuites en Amérique espagnole dans les années 1566-1568. Si les enfants sont au cœur de la stratégie missionnaire jésuite, les pères de la Compagnie se montrent, aussi, volontiers critiques à l'égard de l'arbitraire des autorités et des vieux chrétiens par rapport aux morisques et différencient les indiens selon leur situation dans une «hiérarchie des civilisations " (selon Acosta par exemple). L'étude précise des écrits d'Ignacio de Las Casas montre comment ce jésuite, morisque élevé et admis dans la Compagnie de Jésus, critique les méthodes utilisées par le pouvoir pour l'assimilation et l'évangélisation des morisques et propose des solutions. Partant de l'analyse de l'échec de la conversion des nouveaux chrétiens et de l'attitude négative des vieux chrétiens, il propose cinq solutions : l'arrêt de toute discrimination culturelle, sociale et économique à leur égard, une meilleure formation des prêtres chargés de leur conversion, la lutte intellectuelle contre l'islam et non le mépris, l'éducation et la formation chrétienne des enfants, l'apprentissage de l'arabe pour les futurs prêtres engagés dans la mission. Ces principes sont évidemment liés à un courant porté en particulier par certains nouveaux chrétiens proches des jésuites face à la montée en puissance du durcissement des positions contre les morisques dans les années qui précèdent 1609. Ces éléments qui sont plus que de simples rappels historiques permettent d'analyser comparativement les traités d'Acosta (concernant les indiens) et de Las Casas (pour les morisques). Dans les deux cas, on retrouve la méthode jésuite: le souci d'une bonne communication par l'apprentissage des langues, la connaissance de l'Autre et le remodelage de l'individu par l'éducation. 